\title{
Interview with Denise Britz do N. Silva
}

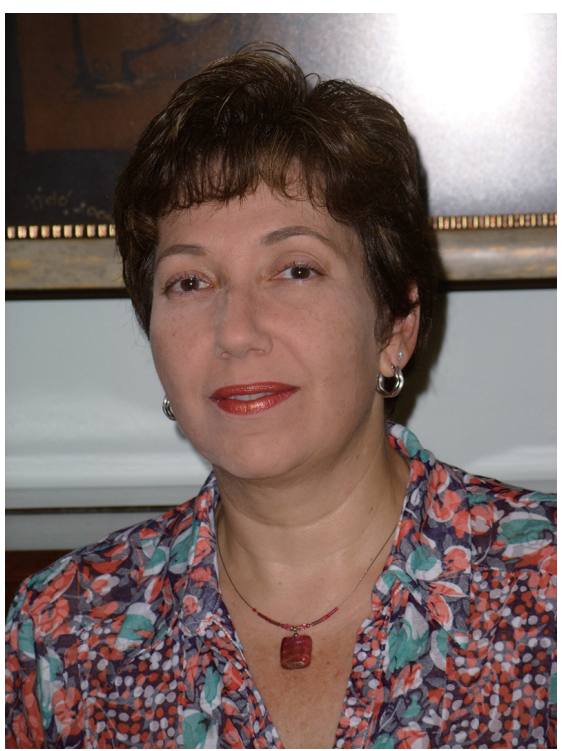

Denise Silva is a principal researcher in the National School of Statistical Sciences in the Brazilian Institute of Geography and Statistics (IBGE). She has extensive experience teaching undergraduate and graduate students. From 2006-10, she worked as a principal methodologist at the UK Office for National Statistics (ONS) and as a lecturer at the University of Southampton. Her main areas of interest are official statistics, survey methods, statistical modelling for the social sciences, small area estimation and time series analysis.

Interviewers: You were born and raised in Rio de Janeiro, Brazil? You attended the National School of Statistical Sciences and got a degree in statistics. How did you get into the field of statistics? Were you encouraged by your parents?

I had all my education in Rio de Janeiro up through my master's degree. Math was my favorite subject. I always liked math. My father was a physician. He would say, "It is so different. I like biology, and you like math." My mother was a nurse and my older sister, my only sister, was studying business administration, so a career in math was not a tradition in my family.
My mother had graduate degrees in both nursing and teaching. She got me interested in statistics.

My mother told me about Florence Nightingale 1 and about how this patroness of the nursing profession kept records and statistics about what was going on in the wars. In essence, Florence Nightingale collected public health statistics.

The school where I studied statistics early on and where I now work (the National School of Statistical Sciences of the Brazilian Institute of Geography and Statistics (IBGE)) is close in location to the hospital where my mother worked for more than 25 years. My mother found the school for me when I was about 14 years old, when I was ready to go to high school. She told me that there was a school nearby the hospital that taught statistics and that it was supported by IBGE. She knew it was a good school and she thought it would be a good school for me since statistics is so closely related to math. She suggested I give it a try. I did, and this is how I discovered statistics.

The National School of Statistical Sciences was inaugurated in March of 1963 and besides offering an undergraduate degree in Statistics was also a vocational-technical school on Statistics, Computing and Geodesy. The curriculum was very technical, so there I was, at age 15, being exposed to what you can do with computers and what technology can do for math and statistics. Remember, this was more than thirty-five years ago. It was quite an opportunity. I also discovered that you could go on to get advanced degrees in statistics.

Interviewers: It sounds like you got in on the leading edge of the field at a very early age. Actually, your educational background is quite amazing. You continued on and got advanced degrees in statistics. You even studied abroad. In England.

\footnotetext{
${ }^{1}$ Florence Nightingale (1820-1910) was the founder of modern nursing. She was the first female to be elected member of the Royal Statistical Society. Later she also became an honorary member of the American Statistical Association.
} 
What brought you to seek further education outside Brazil?

Yes, I got my MSc in Statistics from the Federal University of Rio de Janeiro and my Ph.D. in Statistics in the UK from the University of Southampton. It was a natural progression of what I had started.

Interviewers: Was it unusual for a girl to be interested in math and statistics and to be receiving education in math and statistics at an early age?

I was not the only girl in any of my classes. There were many, many girls. Statistics has always been a mixed field as far as gender goes in Brazil. I developed friendships at an early age with many other girls, friendships that have lasted to this date. We are still in touch and see each other, because they also have degrees in statistics. We never thought about whether there were more males than females in our school or in the field.

By the way, since I now work at the school, I have a colleague, senior in age to me, who affectionately calls me 'my girl' because he met me when I was a young student at the school and he has been working there as an administrator for more than forty years.

Interviewers: At some other time, we should interview you about women's role in statistics in Brazil and talk about how young women can get an early start in the field and about cultural perceptions of females in the profession. For now, let us hear more about your work experience. At some point, you put all your education to good use. Tell us about your career.

I was a trainee-statistician in different places, but I started my career as a statistician working for a tobacco company, the Souza Cruz in Rio de Janeiro, one of largest companies in the British American Tobacco (BAT) Company Group. Actually, both my managers were women with degrees from the same faculty as me. At the BAT, I learned to analyze data about cigarettes, studied the components of the cigarettes, and to work with experimental designs. The company had data about the tobacco plantations and tobacco as a crop. Many countries do not have plantation data, but Brazil does.

I started there when I was 18 . I worked during the day, from 7:30 a.m. to 4:30 p.m. and attended school at night (from 6:30 to 10:30 p.m.) to study for my BA degree. I also took classes on Saturday mornings. Many people did that.
I worked at the Souza Cruz for almost four years. Then I moved to the Brazilian Institute of Geography and Statistics because I wanted to get a Master's degree. I now had a baby, my son was two years old at the time, but I was very keen on getting my degree. Time was very important to me. I asked if I could work a flexible schedule, still working eight hours a day, or 40 hours per week, but on a flexible schedule so that I could get to my classes. They told me they could not be that flexible, but they could change my schedule and let me work from 2 o'clock in the afternoon to 10 at night, so that I could study in the morning. With that arrangement, I would be gone from home from early in the morning to late at night and only have Sundays at home. I started looking for another job.

There were openings at the Brazilian Institute of Geography and Statistics and they recruited me for one of the jobs. I am still employed at IBGE. They let me work 40 hours a-week, attending classes in the morning and then come directly to work. I only had to make up for the time I was out of the office. This was a much more reasonable arrangement for me.

I did not have to take all the classes at the same time. It took me longer than other students to get my degree because I spread out my classes, but this is how I did it. Then, after I had my Master's degree, I left for the UK to study for my Ph.D.

Interviewers: After obtaining your Ph.D., you returned to Brazil?

Yes, I returned to Brazil and to IBGE. The Office has a program, it has been in effect for the last 15 years, whereby you are granted a two-year period off to obtain your Master's and a four-year period to obtain your $\mathrm{Ph} . \mathrm{D}$. and I took advantage of that program. It is a great opportunity. You remain an employee. You are being paid while you are off.

The Research Council in Brazil gave me a grant to study and IBGE contributed part of the grant. My salary alone at the time could not have supported a study abroad. I am very thankful for the opportunity. IBGE still supports educational opportunities for our employees. The employees make the commitment that they will return to the office and stay and work for the office for at least as long as they were off.

I never resigned from my contract with the office. I have been working in IBGE since 1987.

Interviewers: In addition to your work as a principal researcher at the IBGE, you also teach.

We have the wonderful and unusual arrangement where IBGE has a School of Statistics. I believe only 
Brazil and France have this type of situation. The school is recognized by the Ministry of Education for undergraduate and post-graduate studies in Statistics and Demography. Financially, it is supported by IBGE. It is a government school. Instead of reporting directly to the Ministry of Education, the school reports to IBGE. We have to follow all the rules for accreditation. We have the same commitments as far as research and evaluation goes as any other educational institution or university in the country. This is where my teaching occurs.

I work part of the time in methodological research and part of the time, I am a lecturer. That is my job. The teaching commitment may vary. It depends on the project you are involved with and your stage in your career.

Interviewers: Is there any one project you can look back on and say that it was your favorite project?

Can I have three? The first project I worked on I really, really liked. I was very fond of it. I started working at IBGE when I was 23-24 years old. I was a very young statistician. IBGE was doing the Economic Census. We had millions of questionnaires to edit. I worked in editing and imputation. It was the first time that I had to mix my statistical training and knowledge with that of practitioners'. I was very young and they were very experienced. I got a chance to test my theoretical knowledge. I really learned a lot. We also supported the preparation of a sampling frame from the Economic Census. This became the sampling frame for our first Retail and Wholesale Trade Survey. It was the first survey to use sampling techniques for the Trade Sector, and I got to work on the entire project. This was in 1988 and I was very proud of that work.

Some years later, I returned from my studies in the UK. At the University of Southampton, I had studied Social Statistics. At the time, they were preparing to offer a Master's degree in Official Statistics. I was able to help introducing a similar degree here. In English, the degree would translate to a degree in Population Studies and Social Surveys. We established this as a Master's degree program and it has now been running for 16 years. Recently, we obtained approval from the Research Council to add a Ph.D. program. We have worked on this for a very long time, so we are celebrating this accomplishment. We have just selected the first students for the new program.

Another project that I worked on, but only for a short time, is the redesign of our household survey from an annual to a continuous undertaking. It has now been established as a quarterly survey in which we visit households every quarter for five consecutive occasions. While we were reformulating our survey and also considering alternative methods for a Demographic Census, we consulted with the US Census Bureau. We had invited speakers to tell us about the American Community Survey (ACS) and we also brought in speakers from France to hear about their methodology for a rolling census.

In the case of the census, we considered introducing the US model where we would have a short form for the head count and then collect the socio-economic characteristics through a repeated sample survey. In the end, the choice of an alternative method for census did not work for us here in Brazil, because people are very keen on keeping the traditional census.

On the other hand, IBGE managed to develop an improved system of integrated household surveys. Previously, there was a monthly employment survey done in six metro areas (the Labor Force Survey) and once a year a household survey. We have put them together and have also created a master sample. We have reformulated the labor force survey and the household survey into a combined quarterly integrated survey.

Interviewers: What are some of the challenges you have faced as a statistician?

One of the challenges of being a statistician is to be understood and be able to communicate statistics to others. Our job is to deal with the public, researchers from different areas and the users of our products. If you talk to the public the same way you talk to your colleagues in the university about statistics, you are not going to be understood. The public may not even know that they need statisticians or statistical methodology to solve a problem.

Another challenge for statisticians is the fact that statistics is not always taken seriously. Because it is an important subject, it is taught within many disciplines and, after taking an introductory course, some people may think they understand all there is to know about statistical methods. Several of my colleagues spend a lot of time trying to convince people that we must be respected as statisticians because we know a lot about the techniques/methodology. I think a better use of time is to show people how you solve a problem through the proper use of statistics, so that they will know for another time the value of statistical knowledge.

Interviewers: Is the field of statistics changing? Do you think your students will meet different challenges from the ones you have faced? 
I think students of today will have a completely different experience as statisticians than we had. Statistical computing has developed a lot. At the moment, in our School, we have an undergraduate program in statistics that we are revising to include, for example, more subjects related to statistical computing, data visualization and data mining. We need to change with time, but also to keep the theoretical and methodological pillars that are the foundation of statistics.

Today, it is easy to talk about everything for ten minutes since information is readily available, for example, on the web. Students want to do simulations right away. They do not want to spend time learning the foundations for becoming good statisticians, learning calculus, algebra, probability theory or other fundamental skills.

As teachers, we also have to learn and change our methods so we can teach the students of today how to become good statisticians of tomorrow. However, we have to keep the fundamentals, hold on to teaching them the methodology, but we have to provide them hands-on experiences at the beginning of the course, so they will be motivated to pursue their studies and do not walk out before the end of the semester.

Interviewers: Other sciences, such as the biological sciences, are dealing with similar issues in their introductory classes. Students are learning in different ways with the information coming to them at a rapid pace. It seems to be a challenge for all teachers worldwide. That being said, do you find that there is a difference between working as a statistician in Brazil and working as a statistician in another part of the world? What do you think statisticians in Brazil can teach statisticians in other countries?

There is a cultural difference between practicing statistics in Brazil as opposed to for example the UK or the United States. A professional statistician in Brazil is expected to know many different areas and be able to work within different areas of statistics. Perhaps this is because there are fewer statisticians here. We are not as specialized. We have to know how to deal with diversity within our work and have to be prepared to do so.

Furthermore, since we have worked for many years in an environment of economic instability, we have learned to work and deal with higher levels of risk. There are projects that we carry out in Brazil or within IBGE, for example, that I believe a National Statistical Office from Europe or United States would never have been able to get started in a similar situation. The risk of starting up some new projects would have been perceived as too high.

Brazil has a population of around 203 million. Brazil has many problems with its infrastructure, with road conditions and communication. Nevertheless, the last census was entirely paperless. We had 200,000 interviewers working with palmtops (PDAs). A risk we were willing to take. Unfortunately, we did not have the planned and expected time to prepare for the census. The budget never comes exactly on time. Do we wait or do we take the risk? Should we miss a decade and postpone the innovations to be implemented in the following census round? IBGE took the risk and worked very hard to make the project work. We are not proud of having to take higher risks but we have certainly learned to work under more risky conditions.

Interviewers: May we ask you some questions pertaining to your professional activities such as your involvement with the IAOS. You are a regional editor for the Journal?

I have been actively involved for only three or four years when I started being an editor of the Journal. My region is the South America. I heard of the IAOS for the first time when I attended a conference in Mexico in 1998. The International Association of Survey Statisticians (IASS) and the IAOS held a conference on Statistics for Economic and Social Development. It was a very good conference. Since then, I have attended other conferences organized by the IAOS such as the Joint IAOS/ SCORUS Conference on Reshaping Official Statistics that took place in Shanghai in 2008 and the IAOS/IASS Conference on Poverty, Social Exclusion and Development in Amman back in 2004.

I am also an associate editor of the International Statistical Review. I am an elected member of the ISI and have served on the ISI Membership Elections Committee. I was a vice-president of the International Association of Survey Statisticians (IASS) from 2011-13 and I am currently vice-president of IASI (Inter-American Statistical Institute). I am also a member of the ASA (American Statistical Association), The Royal Statistical Society, and the Brazilian Statistical Association and the Brazilian Association for Population Studies.

Interviewers: Does IAOS offer its members something not offered by other organizations?

The IAOS focuses on official statistics. That is a unique focus. Official statistics and public statistics are vital for the world. All the topics discussed by the or- 
ganization, at its meetings, in its journal are very important issues for society.

The IAOS brings together professionals from many different backgrounds. I have a friend who teaches economics in Brazil and got her Ph.D. at the London School of Economics. She has also been involved with the IAOS for years because here she gets an opportunity to interact with people from different professional backgrounds. We can work together to make statistics work better for the entire world.

Interviewers: Does that statement capture your vision for the IAOS? Do you have suggestions for accomplishing this goal?

I think promoting the work of young statisticians is a way to accomplish this goal. The Young Statisticians Prize is an asset to the IAOS. We keep encouraging our young statisticians to submit their work, their papers for the competition. Sometimes they are not comfortable doing so, but when they look at the membership of IAOS and see how inclusive it is, they feel they can belong. The IAOS should keep promoting the organization to young statisticians working with official statistics. Making the Journal available via the web, as you have already done, is really important.

The world is changing. The young people may not perceive that they need to belong to a professional organization if they can take in a network or a web-based interest group. It is more and more difficult to attract regular members for a professional organization. These are some of the challenges IAOS and other professional and academic organizations or societies face today. We must have good websites with relevant links. We must offer them something. They may be attracted to the website, to get news there, to have a reason to visit the website over and over again and be part of this community.

Another way to encourage membership in IAOS is to form local membership groups.

Interviewers: In closing, may we ask you some personal questions.

I am married to a statistician. I am married to Pedro Silva who also works at The National School of Statistical Sciences from IBGE. He is the elected president of the ISI. We got our doctorate degrees together abroad at the same time. So I am not very creative! I am a statistician married to a statistician. We discuss statistics at home, but we have learned to separate our family life from our professional lives. And I have a rule! If someone in the office says "Your husband dis- agrees with me about this or that issue" in a meeting or tells me something about his role on a project referring to him as 'your husband', I answer, "Pedro Silva, not my husband, may have disagreed with you about a particular issue." The only one that can use the term 'husband' is me!

Interviewer: When I look at your resume, I realize that you do not have much free time. In the sparse free time that you do have, what are some of your favorite activities?

I like walking, cinema, reading and cooking. We both do. We use our holidays to go to places where we can hike. We do not backpack or camp. I like staying at nice places with good accommodations where we can enjoy walking. Torres del Paine National Park in Chile comes to mind. We have already been there and it is really amazing. We are planning trips to Yosemite National Parks in California this year and perhaps Yellowstone National Park.

Interviewers: You lived in the UK for a number of years. What do you treasure most from that experience? Did you bring new traditions back home with you?

I lived in the UK twice. In 1992-97 and then again in 2006-10. During the first period I was a research student at the University of Southampton. I really value this experience and, when I came back to the UK, I worked at the University of Southampton and at the Office for National Statistics (ONS). In both jobs, I learned so much. I learned how to teach in English. When you are teaching in a language different from your own, you have to be very well prepared. It was a challenge, but I welcomed it. While I was at the University, an opportunity opened to work in the Methodology Division at ONS. I stayed there for three years. It was a true learning experience. I am still in touch with people there. Back home, I try to implement some of the things I learned from my UK experience: the way they structure the work, the methodology discussions and the small area estimation projects. Employed by ONS, I had the opportunity to liaise with EUROSTAT and other National Statistical Offices in Europe. When applying to the ONS job, I believed it would be nice to work there but I did not know I was going to like it as much as I did. I am glad I am having the chance to put this on paper. The reception I received as a statistician and as part of team at ONS was amazing.

The interview concluded by the interviewers and Dr Silva agreeing that no matter where statisti- 
cians work in the world, and no matter what language they speak, there is a common bond and organizations such as the IAOS can foster that bond. We thank Dr. Silva for all her contributions to the field and for spending her Sunday evening talking to us.

The telephone interview with Dr. Silva took place on January 18, 2015. Kirsten West and Katherine Condon conducted the interview.

Kirsten West is a demographer/statistician at the U.S. Census Bureau. Her areas of expertise are population estimation and census coverage measurement. She has worked on the 1990 Post-Enumeration Survey, the 1991 Evaluation Survey, and the 2000 and 2010
Demographic Analysis operation. She holds a Ph.D. from the University of North Carolina at Chapel Hill.

Katherine Condon is a demographer/sociologist at the U.S. Citizenship and Immigration Services (USCIS) Office of Policy and Strategy. She holds a Ph.D. from Florida International University (Miami, FL) in Sociology and Anthropology and has a Master's (and is ABD) from the University of Pennsylvania (Philadelphia, PA) in Demography. Prior to joining USCIS, she worked at the U.S. Census Bureau in the Population Division's Population Estimates and Projection Area's Administrative Records and Methodology Research Branch as well as in the decennial programs area. 